\title{
Is Choosing a Major Choosing a Career or Interesting Courses? An Investigation into College Students' Orientations for College Majors and their Stability
}

\author{
Alanna Gillis ${ }^{*}$ \& Renee Ryberg² \\ 1 St Lawrence University \\ ${ }^{2}$ Child Trends
}

\begin{abstract}
Students' orientations towards choosing their college majors lead them to make different major choices with long-term stratification implications. In this paper, we investigate what orientations students use to choose their majors, how these orientations vary by student characteristics, how stable orientations are across the first year of college, and what mechanisms might explain how orientations change. We use mixed-methods data from an original longitudinal survey $(\mathrm{N}=1,117)$ and longitudinal in-depth interviews with 50 first-year students at UNC-Chapel Hill (N=146 interviews). We find that students rely on many different orientations, including learning interesting things and helping others, and that their most important orientations frequently change during the first year of college. These findings challenge the existing assumption that major orientations are stable and suggest the need to incorporate changing orientations into models of the major decision process if we hope to successfully intervene to disrupt inequality reproduction.
\end{abstract}

Keywords: college majors; major orientations; inequality; higher education

*Contact: agillis@stlawu.edu 
Choosing a college major is a critical higher education decision. College majors shape short-term outcomes such as difficulty of curriculum (Armstrong \& Hamilton, 2013; Lindemann et al., 2016), skill development (Arum \& Roksa, 2011), and friendship networks (Chambliss \& Takacs, 2014; Raabe et al., 2019) as well as long-term outcomes including career paths (Morgan et al., 2013; Pitt \& Zhu, 2019; Roksa \& Levey, 2010), earning potential (Shauman, 2006), and graduate school attendance (Mullen et al., 2003).

Students do not typically consciously think through all the consequences of this decision (Mullen, 2010) but rely on one or two dominant orientations for choosing a major. We use the term orientation to mean cultural ideas students internalize that guide how they choose their major. Examples include choosing a major based on career outcomes or their intellectual interests (Mullen, 2010; Quadlin, 2020). Understanding how students form their orientations towards college majors, and how those orientations change due to social influences, is critical to fully understanding the major selection process and its significant consequences (Quadlin, 2020).

Most studies of college majors focus narrowly on who majors in what (e.g., why women are underrepresented in science, technology, engineering, and mathematics [STEM]; Valentino et al., 2016; Xie et al., 2015), but have not paid sufficient attention to larger cultural processes guiding the major decision-making process. Students are not simply deciding whether to major in biology or sociology; they are guided by multiple overlapping and contradictory orientations that guide students in prioritizing criteria for choosing a major. Previous literature has identified the following orientations: helping people; preparing for career; satisfying parents' desires; accommodating college social life; and studying interesting ideas (Armstrong \& Hamilton, 2013; Mullen, 2010).

Choosing a major can have far-reaching consequences for students' social and economic trajectories. It can also be a decision that perpetuates inequality by race, class, and gender (Mullen, 2010; Pitt \& Zhu, 2019; Roksa \& Levey, 2010). While all orientations towards choosing college majors exist in the social world, some orientations are more salient than others based on students' social positions. For instance, working-class parents generally encourage choosing a major that directly prepares for a career, while middle-class parents generally encourage exploration of intellectual interests (Mullen, 2010).

If students first form orientations and then choose majors, as many scholars have argued (Davies \& Guppy, 1997; Diekman et al., 2010; Kyte \& Riegle-Crumb, 2017; Quadlin, 2020), understanding more about orientations is a critical step to understanding and disrupting this inequality process. Research directly examining orientations for college majors has often assumed that students have static orientations (da Costa \& Stromquist, 2018; Mullen, 2010; Valentino et al., 2016). However, developmental theories suggest that college is a time of developing identity and purpose (Chickering, 1969), indicating that how students approach choosing their major may change as well. If orientations are malleable, they may be a point of intervention to improve equity in 
higher education. Likewise, by better understanding how students choose their majors, practitioners may be able to help reduce the problem of major churning, wasted credits, and delayed graduations (Armstrong \& Hamilton, 2013).

This paper has four motivating research questions. First, we examine students' initial orientations toward choosing college majors when they enter college: (1) What orientations for choosing college majors do students have at the beginning of their first year of college? (2) What characteristics are associated with initial orientations for choosing college majors? Then, we examine whether and how these orientations change over time: (3) Do orientations for choosing majors change during students' first year of college? (4) If so, how do these changes occur? We find that social characteristics, such as a student's gender and race/ethnicity, are associated with different initial orientations. We also find that orientations for college majors are unstable and the importance of various orientations changes over the course of the first year. Students do not hold stable understandings of how to make decisions about their majors but instead respond to changing environments. This malleability means that students can revise orientations based on feedback from others that may help them make better decisions. This may also mean, though, that students are incorporating biased feedback from others that may serve to reproduce inequality.

In this paper, we first review the previous literature on college major decisions and orientations for college majors. Next, we explain our mixed-methods design and analytical plan, describe our findings, discuss the importance of these findings, and conclude about how these findings should shape future research on college majors.

\section{Orientations for Choosing Majors}

Orientations refer to internalized cultural ideas that guide how students choose their major. Colleges have a long list of possible majors, and students use orientations to structure their thought process in thinking through which program(s) are the best fit for them. College major orientations are generally part of a broader framework of students' perceived purpose of a college education (Mullen, 2010). College is a time for developing identity and purpose (Chickering, 1969). Students develop broader identity and sense of purpose in life, and they develop college major orientations to help them approach the major decision in a way that will help them fulfill their future goals.

Orientations do not operate independently, however. The major selection process can be understood as a constrained decision-making process. Beyond their own orientations, students have many other factors influencing their ability to declare a major, such as their academic performance (Armstrong \& Hamilton, 2013). Previous research demonstrates that orientations for college majors are shaped by the type of postsecondary institution a student attends and an individual student's demographic characteristics (Mullen, 2014; Mullen \& Baker, 2018). 


\section{Institutional Characteristics}

Students' major orientations vary across the types of institutions they attend, based on selection effects and institutional structures (Brint et al., 2005; Mullen \& Baker, 2018). Students select into institutions based, in part, on their academic and professional goals, so that students enter different kinds of institutions with different orientations to choosing majors. For example, Mullen (2010) argues that more selective universities are more likely to admit students with a liberal arts' orientation to major as intellectual identity. Meanwhile, students with more vocational orientations tend to select universities that advertise clear pathways between major and careers.

Institutional structures also reinforce major orientations after students arrive. da Costa and Stromquist (2018) find that women-only universities are more likely to frame engineering as a way to improve society while coeducational universities are more likely to frame engineering as a pathway for stable, high-paying careers. In so doing, women's colleges provide an opportunity for the altruism orientation to become more relevant to the decision about an engineering major. Similarly, when institutions name majors based on the corresponding occupation, such as education, nursing, or business (Brint et al., 2005), they indicate to students that they should choose a major based on career goals. More broadly, when institutions of higher education provide students with more options for possible majors, they provide greater opportunities for self-expression to enter the major choice (Charles \& Bradley, 2009). Institutional pressure for students to match their majors to their interests can be seen, for instance, when academic advisors encourage students to major in what they are most passionate about, encouraging an orientation that is based on interest rather than career or other factors (Armstrong \& Hamilton, 2013).

\section{Student Characteristics}

Due to the United States' history of intersecting oppression, major orientations also vary by student characteristics such as social class, gender, and race/ethnicity. Regarding social class, students from middle-class backgrounds are more likely to select majors based on personal interests while students from working-class backgrounds are more likely to do so based on vocation (Mullen, 2014). Likewise, students whose parents have more education are more likely to be oriented toward graduate school aspirations (Mullen et al., 2003).

Regarding gender, men are more likely to be career-oriented when selecting majors than women (Goyette \& Mullen, 2006; Mullen, 2014; Yalcinkaya, 2017). Even when men and women hold similar orientations for choosing college majors, gender differences can still emerge as students often pursue "self-expressive" career decisions (Cech, 2013) or hold gendered intellectual identities (Mullen, 2014). Gender differences in orientations for college majors are also seen with men being more likely to seek fields they perceive as rigorous (Mullen, 2014), women being more likely to choose majors based on their perceptions of faculty (Chambliss \& Takacs, 2014), and women being more likely to end up in majors that allow them curricular flexibility (Mann \& DiPrete, 
2013).

Regarding race/ethnicity, Asian students are more likely to choose majors that will lead to higher post-college income potential (Goyette \& Mullen, 2006), likely due to the fact that many Asian students come from immigrant families who expect them to choose a college major that will enable social mobility (Xie \& Goyette, 2003). Due to a long history of being excluded from high-quality K-12 educational opportunities, Black and Hispanic students may enter college academically underprepared. Additionally, racial discrimination in education leads to Asian students being pushed toward STEM fields (Min \& Jang, 2015) while Black and Hispanic students are pushed away from them (Ma, 2009). As a result, students end up internalizing their teachers' expectations as evidence of their natural abilities (Allen et al., 2013), such that Asian, Black, and Hispanic students may be more likely to choose their majors based on their perceived ability to complete it than White students. Nevertheless, racialized trends have been less systematically studied than gender, as many studies are not designed to include adequate numbers of students of color in their samples to analyze any racial differences.

\section{Major Selection Process}

The major selection process is a dynamic process that unfolds over time. Institutional and student characteristics influence the orientations students are likely to have when they enter college or to form while they are in college; these orientations then influence the majors students select. Before college, orientations are formed based on family, media, and peer socialization. Students have superficial exposure to majors and may begin narrowing down their college major choice based on preliminary orientations, perhaps even choosing their college based on those ideas. Extensive research has shown that many students change their majors during their first year (Astorne-Figari \& Speer, 2019). However, we argue that another important part of the first year of college is for students' orientations about their majors to be challenged or reinforced, as students encounter peers or advisors who hold similar or different orientations than their own. By the end of the first year, students' orientations have largely solidified and they use these orientations in order to pick the major(s) they view as best fitting their orientations (see Table 1).

The relationship between orientations and majors is not deterministic. Students holding the same orientations may choose different majors due to other constraints they face in the major decision process. For instance, gender gaps in field of study remain even when men and women have the same orientations (Quadlin, 2020). Among students who prioritize money, men are twice as likely to major in engineering fields than women. This may be due to the chilly climate and other factors that push women out of STEM fields (Lee \& McCabe, 2021).

In all, previous research demonstrates that orientations for majors vary by institution and by student characteristics, and that these orientations are associated with majors chosen-though not in a deterministic way. Few studies have addressed the potential 
instability in orientations and studies commonly use data from college juniors and seniors, asking them to retrospectively state what orientations guided their decision. This design does not allow students to report changing orientations over time, nor does it account for retrospective bias. Students who are closer to graduation may overreport the importance of career or graduate school in their decision-making. As a result, Mullen and Baker (2018) call for longitudinal data that follows students from entry into college in order to examine how orientations change over time as a result of being embedded in institutional contexts. This paper seeks to answer that call by examining variation and change in orientations during students' first year.

\section{Table 1: Major Orientation Formation Process}

\begin{tabular}{llll}
\cline { 2 - 4 } Orientation & Before College & First Year of College & Second Year of College \\
\cline { 2 - 4 } Formation & Form preliminary & Discuss college & Orientations largely \\
& orientations based & major thoughts and & solidified \\
& on socialization in & have orientations & \\
& family, media, and & challenged or rein- & \\
peers & forced
\end{tabular}

$\begin{array}{llll}\text { Major Choice } & \begin{array}{l}\text { Superficial exposure } \\ \text { to majors; may take } \\ \text { superficial major } \\ \text { ideas into account } \\ \text { with college choice }\end{array} & \begin{array}{l}\text { Based on orien- } \\ \text { tations, try out } \\ \text { different majors that }\end{array} & \begin{array}{l}\text { Potentially change } \\ \text { fit goals }\end{array} \\ \begin{array}{ll}\text { one that best fits within } \\ \text { orientations }\end{array} \\ \end{array}$

\section{Data and Methods}

We use original mixed-method data, including longitudinal surveys and in-depth interviews of first-year, non-transfer undergraduate students who began at the University of North Carolina at Chapel Hill (UNC) in fall 2018 and who were at least 18 years old. UNC is a highly-selective public research university primarily serving traditional-aged college students between 18 and 23 years old. Students can declare most majors as soon as they begin their first semester on campus, though some require a competitive application process. Those requiring a competitive application process at the time the research was conducted were high status vocational programs like business, public health, and journalism, each of which is housed in its own college outside the College of Arts and Sciences.

All first-year undergraduates who met these criteria $(\mathrm{N}=3,773)$ were sent a survey invitation via email in September 2018; 30 percent of students responded $(\mathrm{N}=1,117)$. All students who completed the survey in the first wave were sent three subsequent surveys in November 2018 ( $\mathrm{N}=618)$, January 2019 ( $\mathrm{N}=625)$, and April 2019 ( $\mathrm{N}=680) ; 371$ students completed all four survey waves. All data was collected in compliance with UNC's IRB. 
Respondents to the baseline survey well represent the demographics of UNC's firstyear student body (see Table 2). Compared to the baseline sample, students who participated in all waves are more likely to be female and White, and less likely to be of historically underrepresented racial/ethnic groups (American Indian/Alaska Native [AIAN], Black, Hispanic, other, or non-Hispanic multiracial), but are similar in terms of parental education and income.

Table 2: Survey Sample Demographics

\begin{tabular}{lcl}
\hline First-year class & Baseline sample & $\begin{array}{l}\text { Students who } \\
\text { participated in } \\
\text { all waves }\end{array}$ \\
\hline & Gender (percentage) & \\
62 & 70 & 79 \\
Not reported & 29 & 21 \\
Not reported & 1 & 1 \\
\hline
\end{tabular}

Female
Male
Another gender

Race/ethnicity (percentage)

Asian or Pacific Islander
Underrepresented race/
ethnicity (American Indian
or Alaska Native, Black,
Hispanic, Other race, or
non-Hispanic, multiracial)
White

Less than a BA

18

16

15

24

23

18

BA

66

61

67

Highest Level of Parental Education (percentage)

Graduate school 22

21

21

35

28

27

43

51

51

Notes. Totals may not sum to $100 \%$ due to rounding.

${ }^{a}$ Class profile statistics are from UNC's Office of Undergraduate Admission's 2018 class profile, available at: https://admissions.unc.edu/apply/class-profile-2. Accessed March 22, 2021. Racial/ethnic groups total more than $100 \%$ in the reported data from UNC.

The interviewees were sampled from respondents to the first survey wave who indicated that they were willing to be contacted about an interview. To maximize diversity, we conducted purposive sampling whereby two students were randomly chosen who fit each demographic category by race/ethnicity (White, Black, Hispanic, and Asian), social class background (working-class, lower-middle-class, and upper-middle-class), ${ }^{1}$ and gender (woman and man). This totaled 48 students and two additional students were selected completely at random to bring the total interview sample to 50 students. The baseline interviews occurred in September 2018 (N=50) with follow up interviews conducted in January 2019 ( $\mathrm{N}=50)$ and April 2019 (N=46).

1 Social class was determined primarily by parental education and secondarily by parental income and student financial aid, as reported by students in the baseline survey. 


\section{Survey Measures}

In order to measure major orientations, students were asked "how important is each of the following for you when trying to decide a MAJOR?" Four response options ranged from extremely important to not at all important. Students assessed 10 orientations found in previous research (Armstrong \& Hamilton, 2013; Mullen, 2010): "lots of high-paying jobs for that major, prepare you well for graduate school, learning about how to help people, major being seen as prestigious, having parental/family approval of major, learning about interesting things, classes being rigorous, classes being easy, liking the professors in that major, and having friends or someone else recommend the major."

For the quantitative analyses, race/ethnicity was re-categorized as: White, Asian or Pacific Islander, and underrepresented racial and ethnic groups (including respondents who selected Black, Hispanic, AIAN, other, and multiple races). While we would have liked to maintain Black and Hispanic as separate categories, our sample size did not allow us to do so. The complete sample included 63 Black students, 87 Hispanic students, and 79 students who identified as AIAN, other, or multiple races.

\section{In-Depth Interview Structure}

Across waves, interviews lasted approximately 45 minutes and students were asked about their academic experiences in classes, major aspirations, and post-college aspirations. The interviews provided an opportunity to understand student's own perspectives about how they made their major choices, as well as expand on richer details of how their process unfolded over time. The interview sample of 50 students was $52 \%$ male and $48 \%$ female. Their social class backgrounds were 34\% working-class, $32 \%$ lower-middle-class, and 34\% upper-middle-class. Their racial/ethnic identities were $32 \%$ White, 26\% Black, 24\% Hispanic, and 24\% Asian.

\section{Analytic Plan}

The first set of quantitative analyses examined the distribution of initial major orientations and how these orientations are associated with student characteristics using the baseline survey, to minimize the number of students who declared a major before we measured their major orientations. This analysis relied on baseline survey respondents who responded to every orientation item and had demographic information ( $\mathrm{n}=983)$. First, we examined the distribution of initial major orientations at the baseline survey descriptively (research question 1) and then used a series of ordinary least squares (OLS) regression models to predict how demographic characteristics were associated with orientations (research question 2). We also examined this relationship using a series of ordered logistic regressions, since the importance of the orientations is measured on an ordinal scale. The results are very similar between the two methods; we present the OLS results for ease of interpretation. We repeated these analyses again with the subset of students who responded to all waves of the survey to facilitate comparison. 
In all analyses, we treated White students and male students as the reference categories to aid readers with interpretation, while recognizing that this risks reifying whiteness and masculinity as normative. These models used a Bonferroni correction to reduce the chance of false positive results.

The second set of analyses, into whether major orientations change over time (research question 3), focused on respondents who responded to all four waves of the survey. We examined the relationship between orientations across waves descriptively, by graphing the proportion of respondents who endorsed each orientation as extremely important at baseline and, among those, who maintained that belief. Similarly, we graphed the proportion of respondents who endorsed each orientation as extremely important at the fourth wave and, among those, how they arrived at those views.

All analyses of the survey data are unweighted using listwise deletion. As such, these results are not generalizable to the first-year student body at UNC, a purposeful choice by the authors, as the results would not be generalizable to other campuses even if they were generalizable to UNC.

We conducted semi-inductive coding of major orientations to analyze the interview data at all three waves. We coded for orientations we knew existed based on prior research, and allowed new orientations to emerge organically from the data. To do so, each digitally recorded interview was first transcribed verbatim. The first author and two research assistants then conducted open coding on transcripts to generate a list of orientations students had in Wave 1. Once complete, we created a codebook of all orientations and trained using Dedoose's code training feature until we reached sufficiently high inter-rater reliability scores (above 0.85 agreement). After training, we completed the systematic coding of all transcripts in all waves of the interview sample. Once all transcripts were coded, the first author and four undergraduate research assistants examined changes in orientations over time by individuals. All names are pseudonyms and some quotes are lightly edited to remove false starts and filler words.

\section{Results}

\section{RQ1: Orientations for College Majors}

In the baseline survey, three-quarters of respondents reported that learning about interesting things was extremely important when choosing a college major (see Figure 1). Approximately 50 percent indicated that helping people or preparing for graduate school were extremely important to them. The next orientations most frequently identified as extremely important were high-paying jobs (30 percent) and liking the professors (26 percent). Less than 15 percent of respondents reported that the remaining orientations were extremely important to them, including the orientations of parental/ family approval, someone recommending the major, easy or rigorous classes, and prestige. Results were similar when examining the subset of students who responded to all survey waves. 
Figure 1: Major Orientation Importance, Wave 1

A. Among All Respondents to Wave 1, n=983

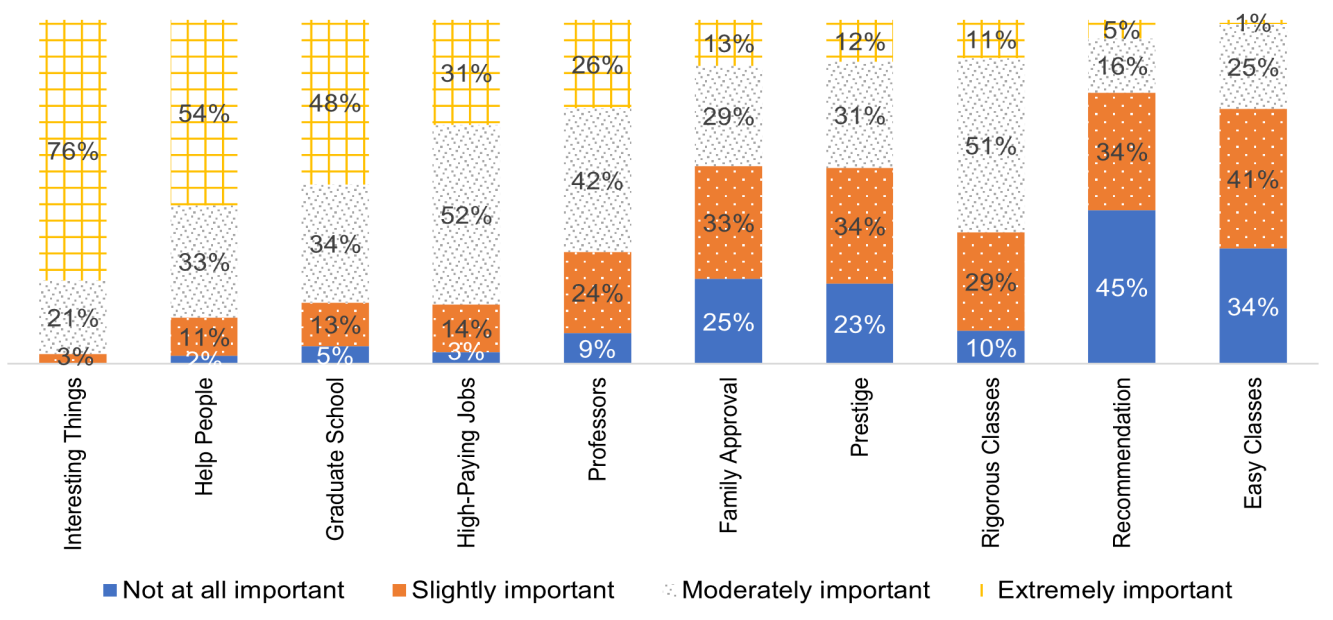

B. Among Respondents in All Waves, $n=307$

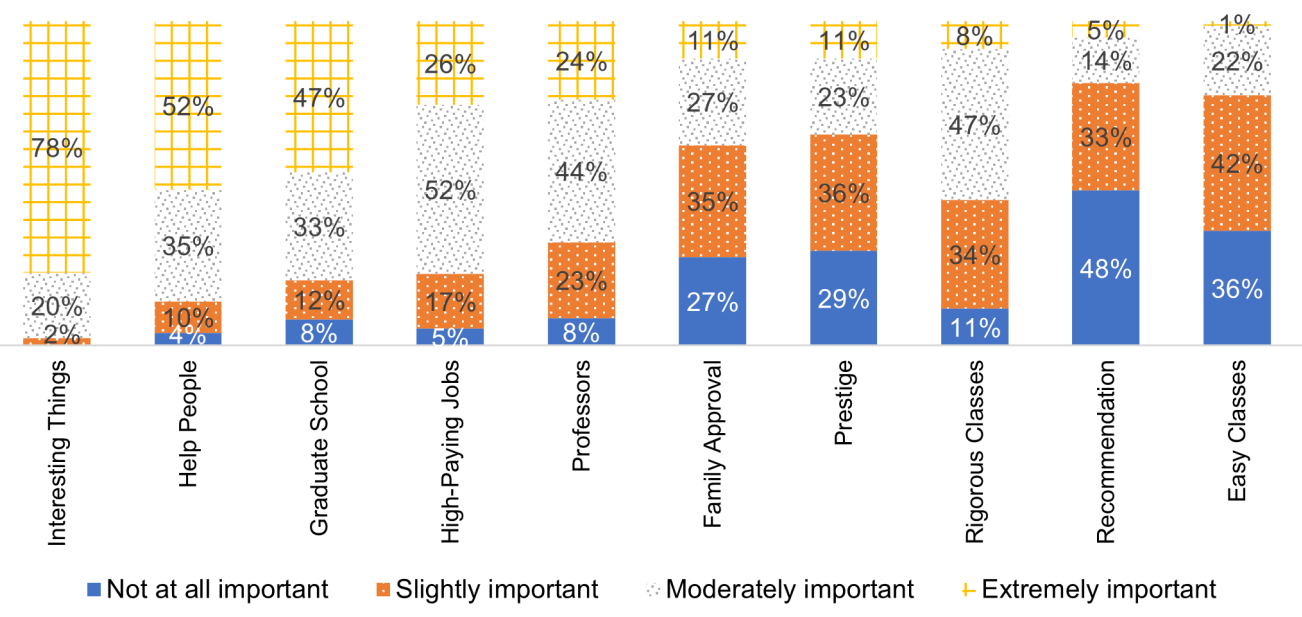

In the baseline interviews, the interesting orientation and career orientation were by far the most commonly mentioned - a finding parallel to the survey results. Han, an upper-middle-class Asian man, articulated the interesting ideas orientation: "I realized I wanted a curriculum that would allow me to explore initially and would have opportunities for me to declare a major in whichever field I ended up liking the most." In contrast, Kwadwo, a working-class Black man, used the career orientation: "I would probably major in biology. I would say biology is one of those majors that can be the baseline for a lot of careers. So it'd be pretty useful."

Other orientations commonly discussed included graduate school, social influence of a non-family member, and family pressure. The graduate school orientation was common for students with medical school aspirations, though several used this orientation to 
structure their major decision to prepare for law school or research-orientated graduate programs. For instance, Elena, a working-class Hispanic woman, explained that she tried to decide her major based on what best prepared her to attend medical school in the future:

I have definitely been asking them about which pathway they see as best for doing research in neonatology and aiding the health disparities that do exist. And I have been speaking to academic advisors as well about what they think would be best for me because I want to go to graduate school and med school.

When students discussed social influences outside of family, they typically discussed the influence of an older student, an instructor, an advisor, or a mentor from the community. For instance, Lila, a working-class Asian woman, explained that she chose biology due to an influential teacher in high school:

It was really my AP biology class because the teacher is my absolute favorite teacher that I've ever met. She was very strict and it was very difficult, but it made me learn more. And it made me actually want to go deeper into the research.

Parental pressure was also a guiding orientation for many students as they sought to choose their majors. For instance, when Stephanie, an upper-middle-class White woman, was asked whether she considered a sociology major, she responded:

I don't think my parents would pay for me to have a sociology degree... They told me, 'Unless you know that you'll get a job when you graduate you cannot take that major'...I personally would love to take it. I just don't think my parents would let me.

In contrast with the survey results, relatively few respondents brought up wanting to help people as a reason for choosing their major. It came up once for every 10 times that the interesting ideas orientations came up and was only the seventh most-commonly mentioned orientation. Diego, a lower-middle-class Hispanic man, explained that he chose public health due to his desire to help people after attending a majors expo during orientation:

My mom asked me, 'What is public health?' And [the major representative] said, 'Imagine that you're at a river and people keep on drowning and falling and no one knows why. And the doctors are the ones that come and resuscitate and save their lives, but public health professionals are the ones that askthe question, why did they fall into and why are they dying?' So I thought that was really, really interesting because I've always had a passion for helping people and wanting to work with people.

While few students explained their major choice as inspired by wanting to help people, many discussed it regarding their career aspirations. Responses were only coded as helping people orientation in this analysis if they talked about it in connection to 
major or major/career, but not if they only talked about it related to career aspirations, as career orientations are outside the scope of this paper.

An orientation not included in the survey emerged during the semi-inductive analysis of the interviews: the student feeling they had the right skills or aptitude for the major. Having the right skills/aptitude refers to students expressing that they have (or lack) the skills/abilities they believe are necessary to complete a particular major. This orientation came up most commonly after students began their college-level courses. For instance, Tiffany, an upper-middle-class White woman, explained that she entered college planning to pursue a chemistry major. However, during an interview during her first semester she feared she was not good enough at math to be able to complete the major. Instead, she changed to biology, a major that requires less calculus: "I'm majoring in chemistry right now, but I'm definitely changing it to biology because I'm in calculus right now and it's already a mess." Students spoke about skill sets including math, writing, abstract thinking, and computing. While students sometimes discussed these skill sets as assets encouraging them to pursue a major, they more often expressed concerns that the lack of skill sets would be barriers to pursuing majors, similar to Tiffany.

\section{RQ2: Orientations for College Majors by Social Characteristics}

Table 3 presents OLS regression results predicting how important each orientation is to students at Wave 1 based on their demographic characteristics. Very similar results from the analysis using ordered logistic regression are presented in Table A1. Below we discuss results that are significant in both analyses.

Table 3 on next page. 


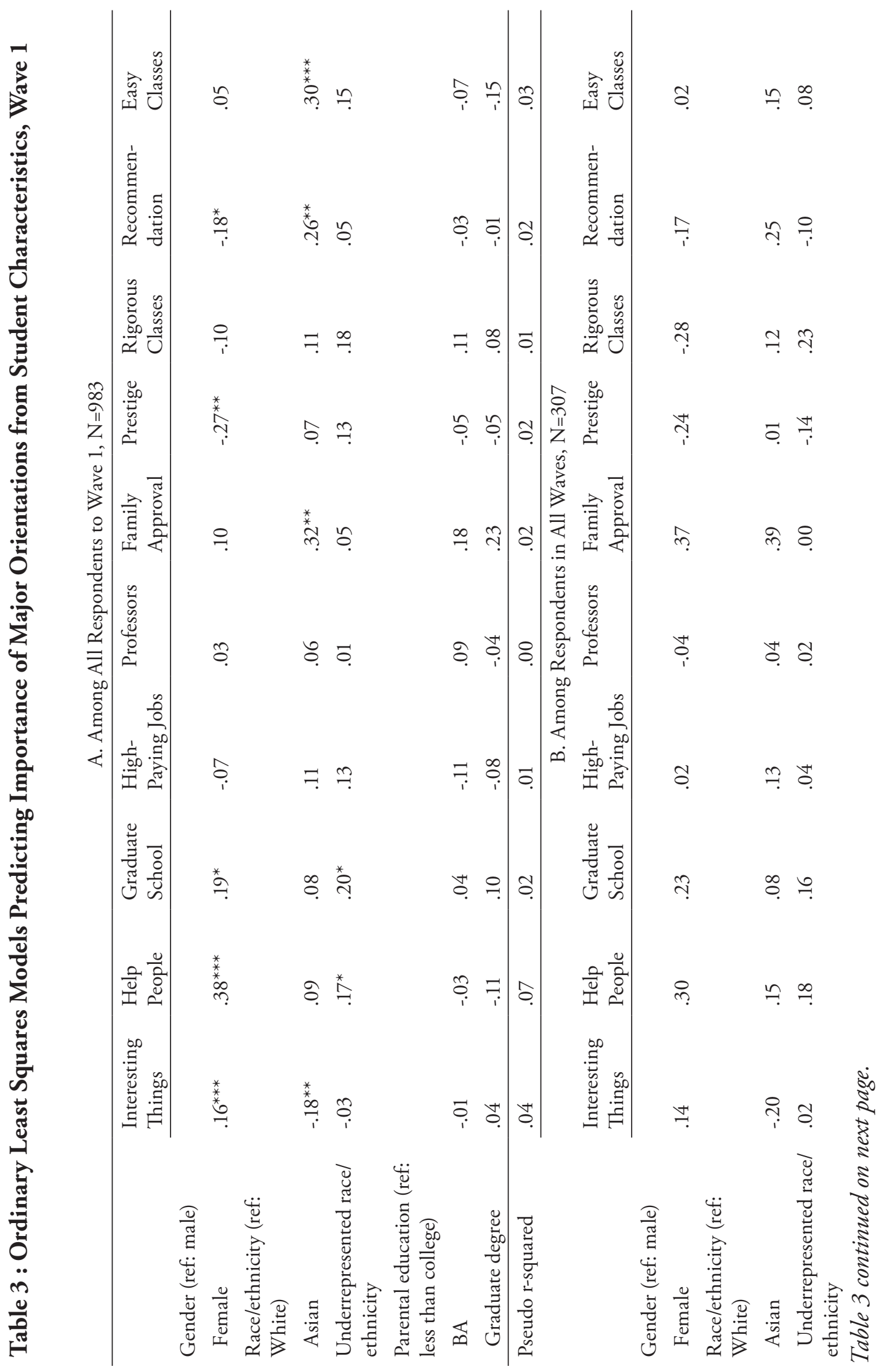




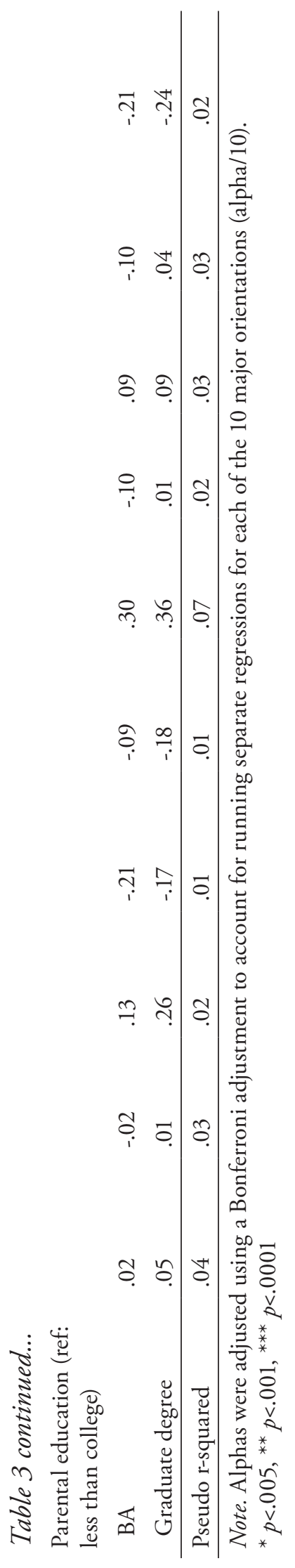


Women rated the orientations of interesting ideas, helping people, and graduate school as more important to them than men. Seventy-nine percent of female respondents indicated that interesting courses were extremely important to them, and 61 percent indicated that helping people was extremely important as compared to 67 and 38 percent of male respondents, respectively. Meanwhile, men were more likely to highly rate the orientations for prestige and receiving a recommendation for the major.

Asian students reported more social influence than White students, reporting family approval and major recommendation being more important than White students. Asian students also rated the classes being easy orientation as more important and were less likely to report interesting ideas being important. Students from historically underrepresented racial and ethnic backgrounds were more likely to report that graduate school is important when choosing a college major than White students.

Students' college major orientations are not closely tied to their parents' education. ${ }^{2}$ These demographic findings are similar among the subset of respondents who responded to all waves of the survey; however, none of these findings are statistically significant, likely due to the small sample size $(\mathrm{n}=307)$.

\section{RQ3: Changes in Orientations Over Time}

For each of the five most popular orientations, Figure 2 presents the proportion of respondents who rated each orientation as extremely important at each wave, among those who indicated it was extremely important at baseline. The indicators that were most popular at baseline were the most stable over time, particularly the orientations about interesting ideas and helping others. Among those who endorsed interesting ideas as extremely important at baseline, 87 percent retained this view at Wave 2, 84 percent at Wave 3, and 85 percent at Wave 4. In contrast, the orientations that were less popular among all respondents were less stable over time.

Figures 2 and 3 on next page.

2 We conducted a sensitivity analysis collapsing parental education into those with at least a Bachelor's degree and those without a Bachelor degree and still found no significant associations with college major orientations. 
Figure 2: Percentage of Respondents who Indicated that the Major Orientation is Extremely Important to Them, by Wave, Among Those who Indicated it was Extremely Important at Baseline

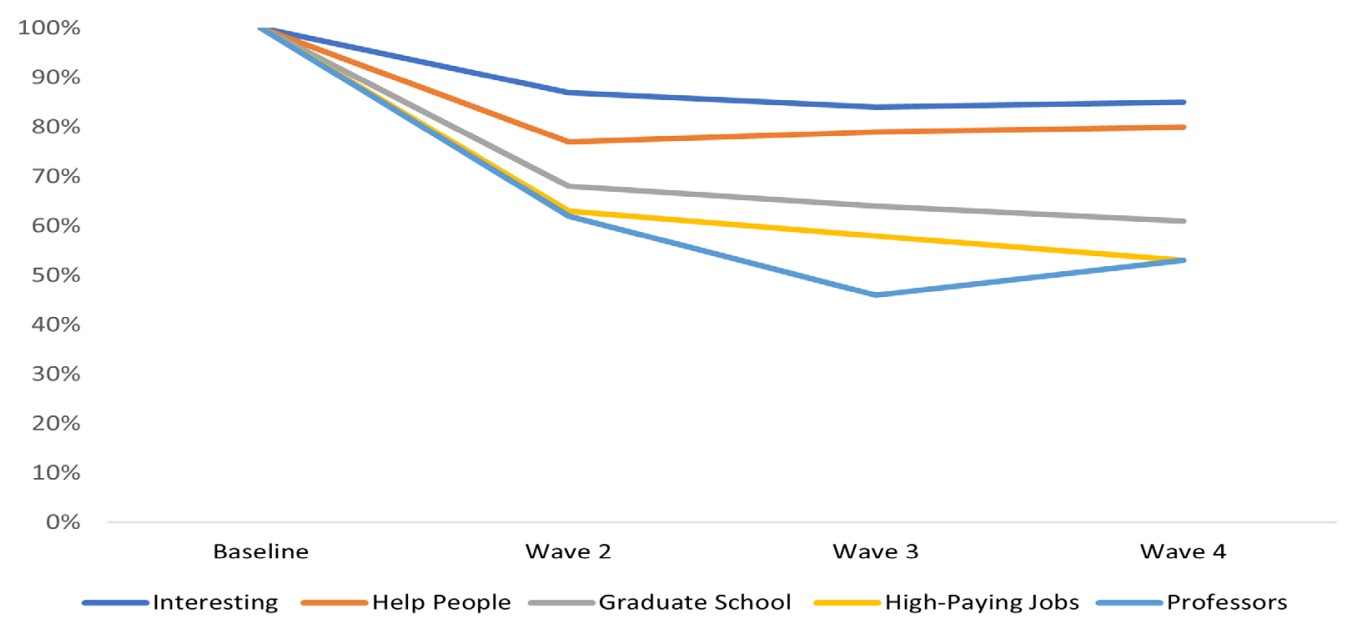

Figure 3 takes the opposite perspective and presents the proportion of respondents who rated each orientation as extremely important at each wave, among those who indicated it was extremely important at the end of their first year in college (Wave 4). Again, the least popular orientations are less stable over time.

Figure 3: Percentage of Respondents who Indicated that the Major Orientation is Extremely Important to Them, by Wave, Among Those who Indicated it was Extremely Important at Wave 4

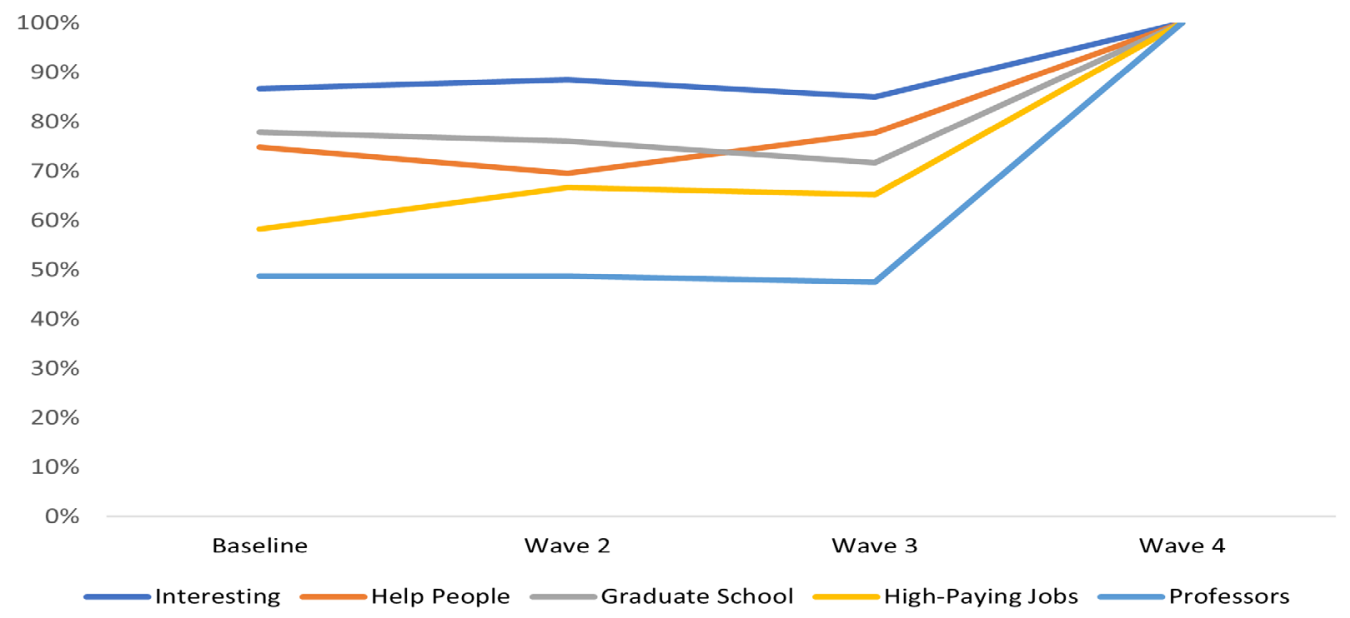

\section{RQ4: Suggestive Mechanisms for Change Over Time}

To understand how students changed their major orientations, we turned to the student interviews, where a few common mechanisms emerged. First, a barrier may prevent a student from implementing their intended major, requiring the student to rethink their major and possibly their orientations. For example, Alejandro, a Hispanic man from a 
working-class background, was originally primarily oriented towards career and interesting courses while his perceived skills/aptitudes were not important orientations guiding his choice. In September he described his thoughts about his major in this way:

I decided that I was interested in something in the medical field sciences specifically, either becoming an anesthesiologist or a pediatrician... Right now I'm leaning towards biology ... so I looked at the requirements and prerequisites for a chem[istry] major and a bio[logy] major and then I looked at the specific classes that are required from each. So I'm taking a cross section of both of them to see which one I enjoy more or which one is more interesting.

Starting college, his career aspirations to become a doctor guided him toward fields like biology and chemistry. However, based on his bad academic experience in introductory chemistry, skills/aptitude rose in importance as an orientation. In January, he explained he needed to choose a new major that does not require chemistry skills, possibly nursing: "I really need to go talk to an academic advisor because I'm actually confused and lost because coming in, my two good subjects [were] biology and chemistry, but chemistry at UNC is just a whole different story, so I was just like, no.”

Similarly, Jayden, a Black man from a working-class background, entered UNC planning to study business to help his career path. After his first semester math course, a prerequisite for the business major, he realized that he would not be successful on this path and he needed to find something he enjoyed more. He explained in his January interview,

I started in business math and it was supposed to be one of the simpler ones ... I took the equivalent in community college but I passed it with a $\mathrm{C}$ [and therefore had to retake the course]. ... and I realized I hate math .... And I can't do more into the theory. It was me and this other girl in the class and we would continuously work together, especially when preparing for the finals and midterms and doing the homeworks together and we would spend hours and I ended up going, 'If this is just the beginning of math in all reality, I don't enjoy it and I don't feel like it's good for me to keep going down this route. Let's see what else interests me.'

Despite tremendous effort and having taken the class before, Jayden was not able to succeed in the class. This barrier to his business-major aspiration made him realize that he must choose a field he finds interesting or he would not be able to succeed, pushing him toward an interesting orientation.

Barriers leading students to reconsider their majors and orientations were more common for working-class students. Working-class students were more likely to struggle academically, as their high schools were far less rigorous. Due to their different cultural capital, they may also struggle to navigate institutional problems when they arise, such that academic struggles can become insurmountable obstacles.

Alternatively, students might change their orientations because they encounter new op- 
portunities that encourage them to think differently. For instance, Malik, a Black man from a lower-middle-class background, was enrolled in two geography courses in his first semester by chance:

Last semester I ended up in two geography classes, completely random because I wasn't available to sign up for classes during my registration period because I was gone out of town [without internet access] and I got placed into those two geography classes randomly.

He "completely loved" the two courses, which took him by surprise. During his first interview, he was primarily concerned with choosing a major that would aid his career interest in government, such as public policy. However, his deep love of his geography courses provided an unexpected opportunity to reconsider his major choice, and his love for the classes became the driving factor in his major choice.

Aniyah, a Black woman with an upper-middle-class background, also encountered a new opportunity that changed her thinking. She entered college focused on choosing a major that would best prepare her to apply to medical school. She explained in September, "I started off as a bio[logy] major as literally every single student, who ever comes here for STEM ... because I want to become a doctor." Her only salient orientations were career and graduate school. By January she added another salient orientation: recommendation by someone else. She explained that she met an Exercise and Sports Science (EXSS) major and realized that she valued that student's advice:

She was a junior here and she's an EXSS major who originally - who had just actually switched to the [EXSS] major and she was telling me she was premed as well, woman of color, and we had the same interests and likes and I was like, 'Oh, what's the major like so far?' She's like, 'I really, really like it.' ... so I looked into it.

Prior to meeting this student, who became her mentor, Aniyah thought of choosing a major as a highly individualized decision. In September, she systematically went through the course catalog by herself to decide the best fit for her goals:

It was really time consuming, but I made a chart of how many credits I needed for the major. This is how many classes that I've taken for each ... okay, now let me look what class do I already know I'm not going to want to take from these majors.

After meeting a student mentor, though, she realized that she should value the opinions of people that she trusts in making her decision. This new-to-her orientation of social recommendation led her to decide to switch her major to EXSS about a week after meeting her mentor.

Students changing orientations due to new opportunities happened more frequently to lower-middle and upper-middle class students, as unexpected events could turn into opportunities rather than barriers when they had the academic preparation and cultural 
capital to successfully learn about and capitalize on these opportunities.

Students may also change their orientations in their first year because new personal connections, such as friends or academic advisors, encourage new orientations. For instance, Allison, a White woman from a working-class background, entered college focused on well-paid careers. She explained that she only took her interest in English seriously as a possible major once she discovered that it was possible to get a well-paid job as an English major. However, as Allison made new friends in college, she became exposed to new ways of thinking about her major. Her new friends and an academic advisor encouraged her to choose her major based on her interest in courses rather than career prospects. She explained, "Most the advice was like, 'Go take your classes and see what fits and what you like." Because of the influence of these new friends and her academic advisor, she increased the emphasis on the interesting courses orientation by January of her first year.

Josh, a working-class White man, explicitly described tension between the advice he received from his parents and his friends at UNC:

My parents have a very traditional [orientation]; go to school and get a good job so that you can pay off your student loans, which is also pretty much my idea because I grew up in that environment. My friends are the same age as me, so they're way younger and more optimistic and are like, "Pursue your dreams, do communications degree and then try to get into a film program or something" and I'm like, "Mmm."

Working-class students, in particular, are likely to experience a change in orientations after interacting with new people because their working-class background encourages a pursuit of a college degree as a pathway to a good middle-class job, while their peers from middle-class backgrounds are more likely to encourage them to consider college a time for intellectual exploration. As a result, they feel tension about which orientation to pursue. Josh flipped back and forth between the importance of the career and interesting orientations across all three interview waves, seemingly not having settled that tension by the end of his first year.

These findings from the qualitative data are consistent with the survey data. Although it is nonsignificant, there is a suggestive correlation between working-class background and prioritizing high paid jobs at baseline. Additionally, as shown in Figure 2, the interesting orientation was much more stable in its position as extremely important than the jobs orientation: nearly half of students who entered college saying high paid jobs were extremely important no longer indicated the same in the last survey wave. Meanwhile, less than 20 percent of students who said that interesting courses were extremely important decreased that importance.

\section{Discussion and Implications}

This study extends previous research on orientations for college majors, revealing the 
most important orientations that guide students' decisions in the first year and how those orientations change over time. We learned from both student surveys and interviews that, at the beginning of their first year, the following major orientations were most important to students: learning about interesting things, learning to help people, preparing for graduate school, and preparing for high-paid jobs. Believing that they had the necessary skills or inherent aptitude to succeed in a major was also an important consideration that emerged from interviews with students. Women were more likely than men to value interesting courses, learning to help people, and preparing for graduate school; students from underrepresented racial/ethnic backgrounds were more likely than White students to value preparing for graduate school and learning to help people; Asian students were less likely than White students to value interesting courses; but, unlike prior research (Armstrong \& Hamilton, 2013; Mullen, 2010), we did not find significant relationships between parental education and student orientations.

\section{Malleability of Orientations}

While prior research assumed that orientations were stable (da Costa \& Stromquist, 2018; Mullen, 2010; Valentino et al., 2016), we found strong evidence that they are malleable and change throughout students' first year of college. We found the orientations most frequently identified as extremely important were the most stable, while less commonly endorsed orientations were less stable. Two possible explanations account for this finding: (1) Institutions often have a dominant culture with one (or a few) orientations (Mullen, 2010), and students who enter college with the most popular orientations are likely to have those reinforced. Meanwhile, students whose original orientations are less commonly endorsed may have the orientations questioned and possibly revised; (2) Alternatively, the less commonly endorsed orientations had small sample sizes and this may be evidence of a natural regression toward the mean.

The interview data suggest mechanisms for changing orientations. Students may encounter barriers that force them-or opportunities that enable them-to reconsider the major decision process in a new way. Students of color and from working-class backgrounds experienced more barriers requiring them to adapt. Without access to rigorous high schools, they frequently struggled with their first-year coursework. Academic barriers led students to consider new orientations that had not previously been as important in their decision-making process. On the opposite end, students from middle-class backgrounds encountered more opportunities to reconsider their orientations with additional information. Because middle-class students were more likely to have opportunities and working-class students, barriers, middle-class students were more likely to revise their orientations to explore new majors while working-class students were more likely to revise orientations closing them off from majors.

Orientations also changed through conversations with new people. Friends and academic advisors often pressured students to conform to the most popular orientation on campus-choosing a major due to personal interests. While some students felt their horizons broadened from being encouraged to choose their majors based on interests, 
this advice led to difficult tension for many students from working-class backgrounds. In all, regardless of student initial orientations, many students may change theirs or go through a process of critical reflection on how to choose their major. Because college provides an opportunity for development of identity and purpose (Chickering, 1969), this shift in many students' orientations is not surprising, even though it had not been previously demonstrated. Even though we did not find any statistically significant differences in the types of orientations that students had by social class at the baseline survey, the ways that orientations change throughout students' first year do appear to vary by class. These changes may create divergence in final major decisions by the end of college that create inequities in long-term career outcomes.

\section{Implications for Researchers}

Taken together, these results suggest that scholars and advisors need to refine their conceptualization of the major decision process. Major orientations guide the way that students sort through possible majors, but much scholarship focuses exclusively on the chosen field of study (e.g., Valentino et al., 2016; Xie et al., 2015). To truly understand how students choose their majors, we must consider students' orientations and how those orientations constrain the choices students feel are available. Major choices can perpetuate inequality, such as gender segregation by field of study and the associated gender wage gap later in life (Armstrong \& Hamilton, 2013; Goyette \& Mullen, 2006; Roksa \& Levey, 2010). Research on major choices must move beyond what decisions are made to consider how students make the decision. We recommend that future research build upon the foundation here to examine how orientations change within different institutional contexts. It is critical that future research use a larger sample size for quantitative studies to test how changes in orientations differ for students from different backgrounds, such as social class and racial/ethnic background.

\section{Implications for Practitioners}

Understanding how students select their majors can help practitioners, including advisors and professors, have informed conversations with their students. These conversations can be an opportunity to disrupt the inequalities built into the major selection process or may serve to make the problem worse. For instance, students reported in interviews that academic advising is impersonal at UNC, like most research universities, where advisors are responsible for large numbers of students. Students met with advisors for 15 minutes or less, primarily about course selection or major requirements, and had little opportunity to develop relationships with their advisors. As a result, advisors' own orientations toward major selection, which was generally interesting courses, guided conversations. The misalignment between advisor and student orientations led to some students feeling alienated from their advisors, such that they avoided returning to speak with an advisor again and missed out on valuable institutional resources.

However, practitioners can use the findings from our research to avoid this and other 
problems that can arise from student orientations. The skills/aptitude orientation that emerged from interviews with students serves as an example. Upon arriving on campus, most students do not think they need to decide their major based on perceived aptitudes or pre-learned skill sets, as most students did not mention this orientation in interviews, or endorse the easy classes orientation in the survey. Instead, students learn this orientation during their first year-and this fact has troubling implications for inequality. Students have unequal opportunities to develop skill sets before they arrive at college, including writing, quantitative, critical thinking, and computing. Majors should be opportunities to develop skills through coursework, but some students are getting a different message from their college experiences: they learn to interpret academic struggles as individual deficits rather than potential for growth. These perceived deficits often fall along lines of historical inequality and exclusion, such as women lacking the necessary aptitude for math and immigrants lacking aptitude for (English) writing (Allen et al., 2013; Xie et al., 2015). By failing to investigate the orientations underlying major choice, we cannot understand how inequality is reproduced in the major decision, and advisors cannot support their students in making the most appropriate decisions.

Alternatively, by including orientations in discussions about majors, we have additional tools to intervene in the major selection process to reduce inequality. For instance, to combat the skills/aptitude orientation, mentors, advisors, and instructors can encourage a growth mindset in entry-level courses where students learn they have the capacity to learn new skill sets (Dweck, 2016; Gillis, 2019. Additionally, students with career orientations often lack information about how majors lead to careers. Providing students with tools to see career connections in all majors can liberate students from narrow, often gender-based, pathways (Quadlin, 2020). These two examples demonstrate the potential that an increased focus on orientations can have for college major scholarship and improved academic advising.

\section{Limitations}

Despite the strengths of this mixed-methods analysis, some limitations need to be discussed. First, the survey sample size was small, especially longitudinally. With reduced power, alongside our conservative Bonferroni corrections, it was difficult to interpret some results. For instance, the qualitative data demonstrated social class to be a strong predictor of student orientations, as does prior research. Yet, our survey data showed null results, complicating our ability to tell a conclusive story of patterns in students' changing orientations to majors. Likewise, while we improve upon prior research by not simply categorizing race/ethnicity as White/non-White, our three racial/ethnic categories mask important differences between students of color. A second limitation is our single institution case. We cannot generalize the specifics of the study across other institutions of higher education. In fact, we argue that different institutional cases with different student populations would quite likely find different ordering of most important orientations. 


\section{Conclusion}

We build on the current scholarship on college majors that assumes that orientations are stable by demonstrating that orientations are malleable and change throughout students' first year of college. Scholars and advisors need to consider the full college major decision-making process in their work-including not only what majors students choose but also what orientations guide those decisions. By fully understanding how students select their majors at this educational turning point, we can better understand how inequality is perpetuated through this process and intervene appropriately.

\section{Acknowledgements}

The authors would like to extend their enthusiastic acknowledgement of the support from our undergraduate research assistants who aided in data collection, transcript cleaning, and qualitative coding: Rosa Hannah, Sara McCauley, Myklynn LaPoint, Elena Eddington, and Grace Hildebrand. We also thank UNC Sociology's Pilot Grant and Penny and Howard Aldrich Summer Research Fellowship for helping fund part of the data collection. Finally, we thank the two anonymous reviewers who gave thoughtful and encouraging feedback to improve the strength of the paper.

\section{References}

Allen, A., Scott, L. M., \& Lewis, C. W. (2013). Racial microaggressions and African American and Hispanic students in urban schools: A call for culturally affirming education. Interdisciplinary Journal of Teaching and Learning, 3(2), 117-129.

Armstrong, E. A., \& Hamilton, L. T. (2013). Paying for the party: How college maintains inequality. Harvard University Press.

Arum, R., \& Roska, J. (2011). Academically adrift: Limited learning on college campuses. University of Chicago Press.

Astorne-Figari, C., \& Speer, J. D. (2019). Are changes of major major changes? The roles of grades, gender, and preferences in college major switching." Economics of Education Review, 70, 75-93. https://doi.org/10.1016/j.econedurev.2019.03.005

Brint, S., Riddle, M., Turk-Bicakci, L., \& Levy, C. S. (2005). From the liberal to the practical arts in American colleges and universities: Organizational analysis and curricular change. The Journal of Higher Education, 76(2), 151-180. https://doi. org/10.1080/00221546.2005.11778909

Cech, E. A. (2013). The self-expressive edge of occupational sex segregation. American Journal of Sociology, 119(3), 747-789. https://doi.org/10.1086/673969

Chambliss, D. F., \& Takacs, C. G. (2014). How college works. Harvard University Press. 
Charles, M., \& Bradley, K. (2009). Indulging our gendered selves? Sex segregation by field of study in 44 countries." American Journal of Sociology, 114(4), 924-976. https://doi.org/10.1086/595942

Chickering, A. W. (1969). Education and identity. Jossey-Bass.

da Costa, R. B., \& Stromquist, N. P. (2018). Framing engineering: The role of college website descriptions." Social Sciences, 7(1), 1-19. https://doi.org/10.3390/ socsci7010007

Davies, S., \& Guppy, N. (1997). Fields of study, college selectivity, and student inequalities in higher education. Social Forces, 75(4), 1417-1438. https://doi. org/10.2307/2580677

Diekman, A. B., Brown, E. R., Johnston, A. M., \& Clark, E. K. (2010). Seeking congruity between goals and roles: A new look at why women opt out of science, technology, engineering, and mathematics careers. Psychological Science, 21(8), 1051-1057. https://doi.org/10.1177/0956797610377342

Dweck, C. S. (2016). Mindset: The new psychology of success. Ballantine Books.

Gillis, A. (2019). Reconceptualizing participation grading as skill building. Teaching Sociology 47(1), 10-21. https://doi.org/10.1177/0092055X18798006

Goyette, K. A., \& Mullen, A. L. (2006). Who studies the arts and sciences? Social background and the choice and consequences of undergraduate field of study. Journal of Higher Education, 77(3), 497-538. https://doi.org/10.1080/00221546. 2006.11778936

Kyte, S. B., \& Riegle-Crumb, C. (2017). Perceptions of the social relevance of science: Exploring the implications for gendered patterns in expectations of majoring in STEM fields. Social Sciences, 6(1), 1-17. https://doi.org/10.3390/ socsci6010019

Lee, J. J., \& McCabe, J. M. (2021). Who speaks and who listens: Revisiting the chilly climate in college classrooms. Gender \& Society, 35(1), 32-60. https://doi. org/10.1177/0891243220977141

Lindemann, D., Britton, D., \& Zundl, E. (2016). 'I don't know why they make it so hard here': Institutional factors and undergraduate women's STEM participation. International Journal of Gender, Science, and Technology, 8(2), 221-241.

Ma, Y. (2009). Family socioeconomic status, parental involvement, and college choices: Gender, race/ethnic and nativity patterns. Sociological Perspectives, 52(2), 211-234. https://doi.org/10.1525/sop.2009.52.2.211

Mann, A., \& DiPrete, T. A. (2013). Trends in gender segregation in the choice of science and engineering majors. Social Science Research, 42(6), 1519-1541. https://doi.org/10.1016/j.ssresearch.2013.07.002

Min, P. G., \& Jang, S. H. (2015). The concentration of Asian Americans in STEM and healthcare occupations. Ethnic and Racial Studies, 38(6), 841-859. https:// doi.org/10.1080/01419870.2014.941891 
Morgan, S. L., Gelbgiser, D., \& Weeden, K. A. (2013). Feeding the pipeline: Gender, occupational plans, and college major selection. Social Science Research, 42(4), 989-1005. https://doi.org/10.1016/j.ssresearch.2013.03.008

Mullen, A. L. (2010). Degrees of inequality: Culture, class, and gender in American higher education. Johns Hopkins University Press.

Mullen, A. L. (2014). Gender, social background, and the choice of college major in a liberal arts context. Gender \& Society, 28(2), 289-312. https://doi. org/10.1177/0891243213512721

Mullen, A. L., \& Baker, J. (2018). Gender gaps in undergraduate fields of study: Do college characteristics mater? Socius, 4, 1-14. https://doi. org/10.1177/2378023118789566

Mullen, A. L., Goyette, K. A., \& Soares, J. A. (2003). Who goes to graduate school? Social and academic correlates of educational continuation after college. Sociology of Education 76(2), 143-169. https://doi.org/10.2307/3090274

Pitt, R. N., \& Zhu, L. (2019). The relationship between college major prestige/status and post-baccalaureate outcomes. Sociological Perspectives, 62(3), 325-345. https://doi.org/10.1177/0731121418803325

Quadlin, N. (2020). From major preferences to major choices: Gender and logics of major choice. Sociology of Education, 93(2), 91-109. https://doi. org/10.1177/0038040719887971

Raabe, I. J., Boda, Z., \& Stadfeld, C. (2019). The social pipeline: How friend influence and peer exposure widen the STEM gender gap. Sociology of Education, 92(2), 105-123. https://doi.org/10.1177/0038040718824095

Roksa, J., \& Levey, T. (2010). What can you do with that degree? College major and occupational status of college graduates over time. Social Forces, 89(2), 389-416. https://doi.org/10.1353/sof.2010.0085

Shauman, K. (2006). Occupational sex segregation and the earnings of occupations: What causes the link among college educated workers? Social Science Research, 35(3), 577-619. https://doi.org/10.1016/j.ssresearch.2004.12.001

Valentino, L., Moller, S., Stearns, E., \& Mickelson, R. (2016). Perceptions of future career family flexibility as a deterrent from majoring in STEM. Social Currents, 3(3), 273-292. https://doi.org/10.1177/2329496515604636

Xie, Y., \& Goyette, K. A. (2003). Social mobility and the educational choices of Asian Americans. Social Science Research, 32(3), 467-498. https://doi. org/10.1016/S0049-089X(03)00018-8

Xie, Y., Fang, M., \& Shauman, K. (2015). STEM education. Annual Review of Sociology, 41, 331-357. https://doi.org/10.1146/annurev-soc-071312-145659

Yalcinkaya, N. S. (2017). Express yourself or secure your future? Constructions of choice and gender gaps in STEM fields. [Unpublished doctoral dissertation]. University of Kansas. 


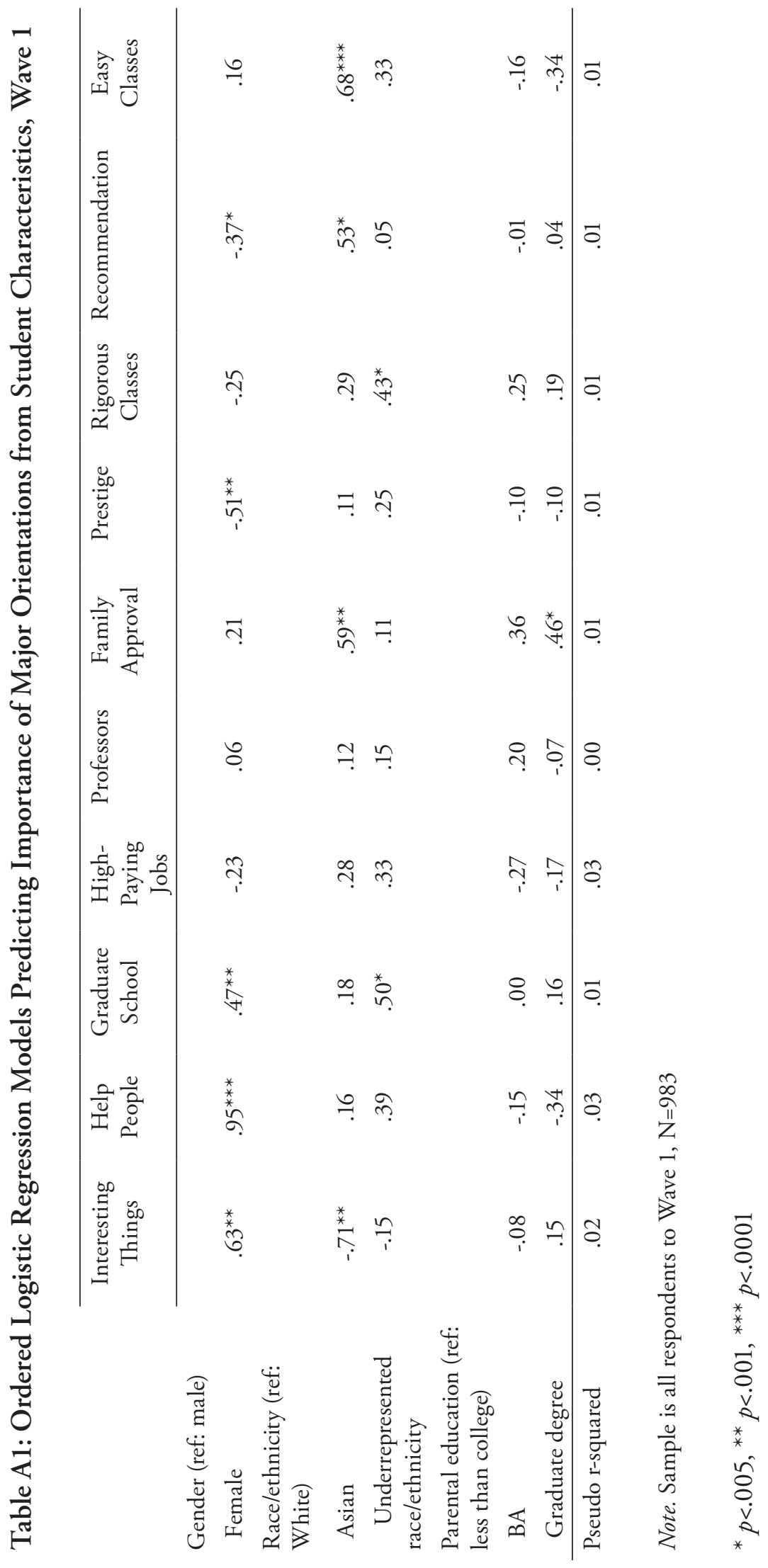

